\title{
Cushing's syndrome associated with carcinoma of pancreas
}

\author{
AlaF KhaN \\ M.B., Ch.B., D.C.H., M.R.C.P.(Ed.) \\ Medical Registrar, Ruchill Hospital, Glasgow
}

IT IS Now generally accepted that malignant tumour cells are capable of producing a variety of substances whose biological activities are identical with those of various endocrine hormones (Morrell, 1964 ; Ross, 1965 ; Anderson, 1966 ; Friedman, Marshall Jones \& Ross, 1966; O'Riordan et al., 1966). As a rule, the secretion of such hormone-like substance is 'inappropriate' in the sense that it is not related to the body's physiological needs and escapes the normal feedback homeostatic control.

Adrenocortical hyperactivity is the most common endocrine derangement and oat-cell carcinoma of the bronchus is, numerically, the most important cause of such malignant Cushing's syndrome. Although carcinoma of the pancreas is a relatively common form of neoplasm, its association with Cushing's syndrome is rare (Hallwright, North \& Reid, 1964). The following report records such a case of fatal Cushing's syndrome secondary to carcinoma of the pancreas.

\section{Case report}

A female, aged 60, was admitted to Ruchill Hospital on 27 December 1966 complaining of nervousness, excessive thirst and swelling of the face during the preceding 7-10 days.

On examination. A lethargic, obese patient with florid complexion and puffiness of the face. No oedema, finger clubbing or striae of the skin. Heart rate $120 / \mathrm{min}$, sinus rhythm, BP 240/ $120 \mathrm{mmHg}$. No clinical cardiomegaly. Lungs and abdomen clinically clear. No visual field defect on testing by confrontation.

Investigations. Hb. $15.4 \mathrm{~g} / 100 \mathrm{ml}$; ESR $9 \mathrm{~mm} /$ hr. Proteinuria $4 \mathrm{~g} / 1$; glycosuria $2 \mathrm{~g} / 100 \mathrm{ml}$. glucose tolerance test-severe diabetic curve. Serum urea $50 \mathrm{mg} / 100 \mathrm{ml}$; sodium 140 ; chloride 85 ; potassium 1.9 ; alkali reserve $41 \mathrm{mEq} / 1$. Blood pH. 7.54 ; $\mathrm{PCO}_{2} 45 \mathrm{mmHg}$; standard bicarbonate $36 \mathrm{mEq} / 1$; base excess + $14 \mathrm{mEq} / 1$. Pituitary fossa and lung fields radiologically normal. Bronchoscopy-negative.

Tests of adrenocortical function. Plasma cortisol (midnight) $69.5 \mu \mathrm{g} / 100 \mathrm{ml}$. Plasma cortisol (09.00 hours) $82.0 \mu \mathrm{g} / 100 \mathrm{ml}$ rising to 121 E $\mu \mathrm{g} / 100 \mathrm{ml}, 30 \mathrm{~min}$ after $0.25 \mathrm{mg}$ of Synacthen given intramuscularly. The 24 -hr output of 17 ketosteroids and 17-hydroxycorticoids was 15.5 and $36.4 \mathrm{mg}$, respectively. On receiving $0.5 \mathrm{mg}$ dexamethasone orally, 6 hourly, the outputs were 20.7 and $39.3 \mathrm{mg}$; on $2 \mathrm{mg}$ of dexamethasone 6 hourly, the corresponding figures were 13 and $18 \mathrm{mg}$. The resting output of 17-hydroxycorticoids was not altered by oral metyrapone.

Clinical course and management. Large doses of oral potassium and soluble insulin achieved a reasonably satisfactory control of hypokalaemia and hyperglycaemia. Her general state, however, continued to deteriorate steadily while her adrenocortical function was being investigated. Gross oedema of the lower limbs and severe muscle wasting became obvious within three weeks of admission. Lucid intervals alternated with periods of profound depression, psychotic behaviour and strong suicidal tendencies. Deep purple striae and a firm, mobile mass in the right hypochrondrium were noticed. Laparotomy was carried out on 16 February 1967, with a view to exploring the right hypochrondrial mass and performing bilateral adrenalectomy. A spheroidal, mobile tumour measuring about 4 in. in diameter was found in the head of the pancreas. The surgeon (Mr Stuart Young) felt that the tumour could not be excised in its entirety and adrenalectomy would not confer lasting benefit. The abdomen was, therefore, closed without further interference. She lost ground steadily and died on 13 March 1967.

Necropsy findings (Dr R. R. Wilson)

'No neoplasm was found in the bronchial tree or lungs despite a meticulous search. Moderate hypertrophy of left ventricle. Brain, pituitary, thyroid, kidneys and liver normal. Adrenals slightly enlarged, together weighing $35 \mathrm{~g}$. Cut surface showed thick cortex with lipoid depletion and obvious vascular streaking, suggestive of increased blood flow. A spheroidal mass, $9 \mathrm{~cm}$ in diameter was found in the head of the pancreas. No metastases. Common bile duct of normal calibre. Ampulla of Vater stenosed but patent. 
Numerous foci of fat necrosis distal to the tumour. Striking dilatation of the main pancreatic duct to an internal circumference of $3 \mathrm{~cm}$ over a considerable length.'

\section{Histology (Professor T. Symington)}

(1) Adrenals: 'Absolutely typical of the ectopic ACTH syndrome associated with Cushing's disease. The gland is tremendously hyperplastic and consists of large hypertrophied compact cells which extend out to the capsule of the gland.

(2) Pancreas: The tumour of pancreas is a typical small-cell carcinoma similar to an oatcell carcinoma of the bronchus. This is the common type of tumour which is associated with hormone production.

(3) Pituitary: The characteristic features of the pituitary are the presence of Crooke's hyaline cells which may or may not be found in the ectopic ACTH syndrome.'

\section{Comment}

The rapid onset of symptoms, the presence of diabetes, hypertension and hypokalaemic alkalosis and the development of oedema, muscle wasting and depressive psychosis were all characteristic of the so-called ectopic ACTH syndrome. Loss of diurnal rhythm of cortisol secretion and independence of pituitary control supported this diagnosis. Because of its frequent association with this syndrome, carcinoma of the bronchus was suspected, but no evidence for its presence was discovered. Excessive obesity of the abdomen had made clinical assessment of abdominal viscera difficult and the pancreatic tumour was appreciated only after the patient had lost a good deal of weight. In such circumstances, it would seem desirable to carry out a barium meal and 'follow through' when no clue to the presence of an intrathoracic lesion is forthcoming.

In view of the clinical picture and the histological appearances of the pancreatic tumour and the adrenal cortex, the Cushing's syndrome in this patient would appear to be secondary to the carcinoma of the pancreas. Pancreatic carcinoma should be considered a possibility when search for an ectopic source of ACTH is indicated.

\section{Acknowledgments}

I am very grateful to Professor Symington, Mr. Young and Dr Wilson for their respective roles mentioned above. My special thanks are due to $\mathrm{Dr}$ T. J. Thomson, not only for his permission to publish this report, but also for his constant encouragement and invaluable help.

\section{References}

ANDERSON, E.G. (1966) Non-metatastic syndromes associated with carcinoma of the bronchus. I. The endocrine system. Hosp. Med. 1, 11.

Friedman, M., Marshall Jones, P. \& Ross, E.J. (1966 Cushing's syndrome, adrenocortical hyperactivity second? ary to neoplasm arising outside the pituitary-adrena $\$$ system. Quart. J. Med. 35, 193.

Hallwright, G.P., North, K.A.K. \& ReID, J.D. (1964 Pigmentation and Cushing's syndrome due to malignang tumours of the pancreas. J. clin. Endocr. 24, 496.

MORRELL, M.T. (1964) Cushing's syndrome associated wit bronchial carcinoma. Postgrad. med. J. 40, 614.

O'Riordon, J.L.H., Blanshard, G.P., MoxhaM, A. NABARRO, J.D.N. (1966) Corticotrophin-secreting carcinomas. Quart. J. Med. 35, 137.

Ross, E.J. (1965) Endocrine and metabolic consequences of carcinoma of the bronchus. Proc. Roy. Soc. Med. 58, 485.

\title{
A medical emergency treated by anti-mitotic drugs
}

\author{
W. S. B. LOWRY \\ M.B., M.Sc., F.F.R. \\ Senior Registrar, Department of Medicine, \\ Royal Victoria Hospital, Belfast*
}

THIS case of malignant tumour is reported since it may be the first of its kind to present in coma and subsequently be resuscitated with chemotherapy.

\section{Case report \\ Miss E.C., a 53-year-old civil servant, was \\ *Seconded from The Northern Ireland Radiotherapy Centre.}

admitted to hospital in a confused state. Two weeks before admission she attended the surgical out-patients' department with a small lump in her neck. At that time chest $\mathrm{X}$-ray and blood picture were normal and Paul Bunnell was negative. There was no further history.

On examination the patient was disorientated in time and place but not in person. Optic fundi were normal. There was no loss of power in the limbs and the deep reflexes were brisk and equal 